\title{
Physical Properties of Handsheets Derived from Coi (Streblus asper Lour.) Pulp Fiber as Papermaking Material Traced from Ancient Times
}

Somwang Khantayanuwong, ${ }^{\text {a,b }}$ Wisanee Boonpitaksakul, ${ }^{a}$ Korawit Chitbanyong, ${ }^{a}$ Sawitree Pisutpiched, ${ }^{\mathrm{a}}$ and Buapan Puangsin ${ }^{\mathrm{a}, *}$

There have been recent attempts to revive the traditional production of handmade paper from the bark of the Coi (Streblus asper Lour.) tree in Thailand. A sheet sample of Coi handmade paper, made from the traditional production, was collected and examined microscopically for the first time. Film-like material and cubic calcium particles were found on the sheet sample surface, which is consistent with the results of the authors' previous research. Meanwhile, handsheets derived from Coi pulp fiber, freshly made in the laboratory, demonstrated a low air permeance and brightness with high opacity due to the film-like material and cubic calcium particles. With a high felting power of Coi pulp fiber coupled with a possible strengthening role of the film-like material, both the beaten and unbeaten fibers were used to form handsheets with high strength. Some potential aspects of Coi pulp fiber suitable for creating a unique Thai banknote paper have been demonstrated, for which further studies are suggested.

Keywords: Coi; Handsheet; Physical properties; Pulp fiber; Streblus asper Lour.

Contact information: a: Department of Forest Products, Faculty of Forestry, Kasetsart University, Bangkok 10900, Thailand; b: Suphanburi Campus Establishment Project, Kasetsart University, Bang Pla Ma District, Suphanburi 72150, Thailand; *Corresponding author: fforbpp@ @u.ac.th

\section{INTRODUCTION}

Siamese handmade paper was first recorded by Monsieur de la Loubère, a French envoy extraordinaire to King Narai the Great of Siam, during the years 1687 and 1688. Popularly known as Coi paper, it was made from old cotton rags and the bark of the Ton Coi (Streblus asper Lour.) tree. The paper was used to make the Thai long book, namely "Samud Coi", by folding it in and out like a fan. Therefore, Samud Coi was not bound, with text usually written under the lines along the length of the folds and not the breadth. During the same time, there is mention of another handmade paper produced from pulp fiber derived from the bark of the paper mulberry (Broussonetia papyrifera) tree, which is found in many Asian countries including Thailand. Coi paper and Samud Coi are unique to Thailand and have been produced and utilized by the Siamese (or Thai people) for more than 330 years (La Loubère 1693; Veeraprachak 1987; Hubbe and Bowden 2009). Such information about the Coi paper or Samud Coi is an important geographical indicator of Siamese wisdom.

Boonpitaksakul et al. (2019) recently reported the chemical properties of Coi bark and the morphology of Coi fiber. Some properties and attributes of Coi fiber in chemical pulping and as paper have been reported, but the physical properties of the Coi paper have yet to be elucidated. This is because both Coi paper and Samud Coi have disappeared from daily use, and there are only a few studies on their cultural and archeological aspects in 
Thai culture and society (Veeraprachak 1987; Srivorapot and Saengtub 1999). However, there have been recent attempts to revive the traditional production of Coi handmade paper at a folk arts and crafts center in Thailand.

Therefore, in this study, in order to compare with the results of the authors' previous research (Boonpitaksakul et al. 2019), a sheet sample of Coi handmade paper derived from the traditional production was microscopically examined. Meanwhile, an investigation related to the physical properties of Coi handsheets produced contemporaneously in the authors' laboratory was conducted and determined. The feasibility study of using Coi pulp fiber as a unique fibrous raw material in the future production of Thai banknote paper was also demonstrated.

\section{EXPERIMENTAL}

\section{Materials}

Sheet sample of Coi handmade paper derived from the traditional production

A sheet sample of Coi handmade paper was observed under a microscope, to explore its surface structure. This sample was produced in 2019 by the traditional method without coating and finishing at Ko Koet Royal Folk Arts and Crafts Center located in the Ko Koet sub-district, Bang Pa-in district, Phra Nakhon Si Ayutthaya province, Thailand, as shown in Fig. 1.

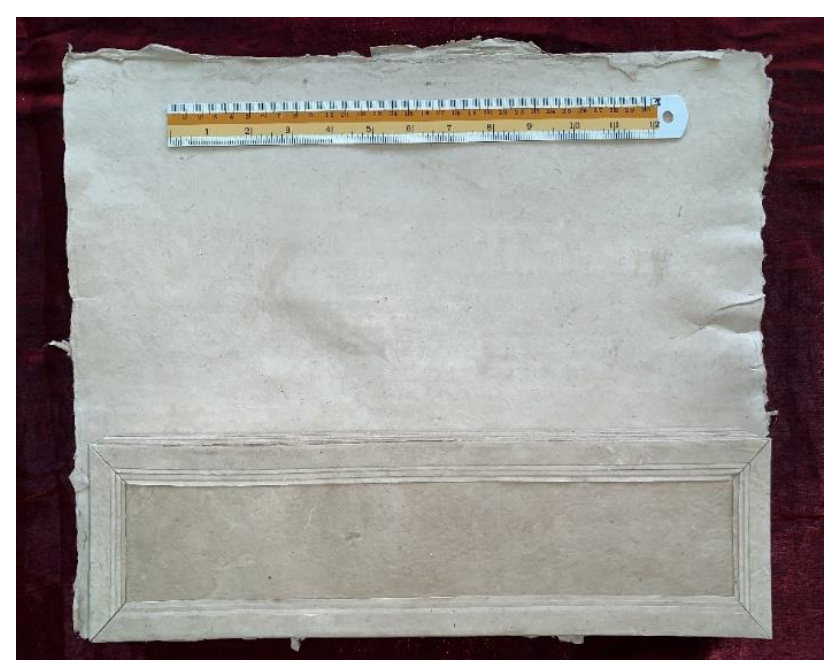

Fig. 1. A sheet sample of Coi handmade paper

\section{Bleached Coi pulp fiber}

Bleached Coi pulp fiber was derived from the unbleached fiber by using three stages of elementary chlorine-free $(\mathrm{ECF})$ bleaching, i.e., $\mathrm{D}_{0} \mathrm{ED}_{1}$ as demonstrated in Table 1. The conditions were designed to achieve a target bleached Coi bark pulp fiber of at least $80 \%$ brightness, according to Thai Industrial Standard, namely TIS 1054-2552 (2009). The unbleached Coi pulp fiber was derived from peeled Coi bark strips subjected to soda pulping by using $14 \% \mathrm{NaOH}$ at a 5:1 liquor to bark ratio and at maximum temperature of $165^{\circ} \mathrm{C}$. The heating time to reach the maximum temperature was an hour, and the maximum temperature was also maintained for an hour according to the pulping conditions stated in our previous research (Boonpitaksakul et al. 2019). The peeled Coi bark strips 
were provided by Ko Koet Royal Folk Arts and Crafts Center located in Ko Koet subdistrict, Bang Pa-in district, Phra Nakhon Si Ayutthaya province, Thailand. Table 2 shows the changes in yield, Kappa number, and brightness of the bleached fiber after the ECF bleaching. In this study, the bleached fiber (obtained after ECF bleaching) was stored in wet state at $4 \pm 2{ }^{\circ} \mathrm{C}$ in a refrigerator for a few days before handsheet making. The chlorine dioxide $\left(\mathrm{ClO}_{2}\right)$ solution was kindly provided by the Environment Pulp and Paper Co. Ltd., Nakhon Sawan province, Thailand. The sodium hydroxide $(\mathrm{NaOH})$ and other standard chemicals in this study were purchased from Merck (Bangkok, Thailand) and were used without further purification

Table 1. The ECF Bleaching Conditions Designed to Obtain over $80 \%$ Brightness of the Bleached Coi Bark Pulp Fiber

\begin{tabular}{|c|c|c|c|}
\hline Bleaching Stages & $\mathrm{D}_{0}$ & $E$ & $D_{1}$ \\
\hline \multicolumn{4}{|l|}{ Chemicals } \\
\hline$-\mathrm{ClO}_{2}(\%)$ & 7.14 & - & 2 \\
\hline$-\mathrm{NaOH}(\%)$ & - & 1 & - \\
\hline Temperature $\left({ }^{\circ} \mathbf{C}\right)$ & 70 & 70 & 70 \\
\hline Time (min) & 60 & 60 & 180 \\
\hline Consistency (\%) & 10 & 10 & 10 \\
\hline Targeted final pH & $1-3$ & 11 & $2.50-4$ \\
\hline
\end{tabular}

Table 2. Changes in Yield, Kappa number, and Brightness of Coi Pulp Fiber Obtained after ECF Bleaching

\begin{tabular}{|c|c|c|c|}
\hline Bleaching Stages & Yield (\%) & Kappa Number & Brightness (\%) \\
\hline Unbleached & - & $28.39 \pm 0.32$ & $25.55 \pm 4.84$ \\
\hline$D_{0}$ & $89.60 \pm 2.06$ & $17.20 \pm 1.27$ & $84.18 \pm 2.22$ \\
\hline $\mathrm{D}_{0} \mathrm{ED}_{1}$ & $87.88 \pm 5.22$ & $16.42 \pm 2.00$ & $89.37 \pm 2.90$ \\
\hline
\end{tabular}

Commercial pulp fibers

Commercial bleached hardwood, softwood, and cotton pulp fibers provided by Thai Paper Co., Ltd. (Bangkok, Thailand) and the Bank of Thailand (Bangkok, Thailand) were also used in this research. These were procured from them to compare the properties of the handsheets with those derived from the Coi pulp fiber. The cotton lint and cotton linter ratio of the cotton pulp fiber was deemed as classified information owing to trade secrets and anti-counterfeiting reasons in the case of banknote paper.

\section{Methods}

Microscopic observations of the sheet sample of Coi handmade paper

The sheet sample of Coi handmade paper was observed under a field-emission scanning electron microscope equipped with energy dispersive X-ray spectroscopy (FESEM/EDX) (SU8020; Hitachi, Tokyo, Japan). The microscopic observations were compared with the surface morphology of Coi handsheet analyzed in previous research (Boonpitaksakul et al. 2019), e.g., the cubic calcium particles left on the surface of Coi handsheet. 


\section{Handsheet making and testing}

Bleached Coi pulp fiber was beaten with a laboratory Hollander beater (Laurentzen and Wettress, Stockholm, Sweden), using deionized water, according to TAPPI T 200 sp10 (2010). Various durations of beating time were considered and included 0, 15, 30, and 45 min, respectively. Freeness was measured at each of the beating time, according to TAPPI T 227 om-09 (2009). A set of 10 handsheets, with a basis weight of $60 \mathrm{~g} / \mathrm{m}^{2}$, were produced from both unbeaten and beaten bleached Coi pulp fibers for each of the beating time durations, according to the ISO 5269-1 standard (2005). All handsheets were conditioned at a relative humidity of $50 \pm 2 \%$ and a temperature of $23 \pm 1{ }^{\circ} \mathrm{C}$ for a week before testing. Handsheet structure was observed by FE-SEM (SU8020; Hitachi, Tokyo, Japan).

The apparent density of Coi handsheet was determined following TAPPI T $220 \mathrm{sp}$ 10 (2009). Handsheet thickness was measured according to TAPPI T411 om-08 (2008) using a precision micrometer (Laurentzen and Wettress, Stockholm, Sweden). Air permeance of handsheets was evaluated by the Gurley method, as specified by TAPPI T460 om-11 (2011), with an oil-sealed-type densometer (model no. 4110N; Gurley Precision Instruments, New York, USA). Surface roughness were determined as stated in ISO 56363 (1992) via an automatic Bendtsen apparatus (Frank-PTI Quality Testing Instruments, Vorchdorf, Austria). Optical properties, including brightness and opacity, were measured by a reflectometer (Model-3; Kumagai Riki Kogyo Co. Ltd., Tokyo, Japan) according to TAPPI T452 om-08 (2008) and TAPPI T425 om-11 (2011), respectively.

The mechanical properties of handsheets, i.e., bursting strength (TAPPI T403 om10 (2010)), folding endurance (TAPPI T511 om-08 (2008)), tearing resistance (TAPPI T414 om-04 (2004)), and tensile strength (TAPPI T494 om-06 (2006)), were determined by using a bursting strength tester (Laurentzen and Wettress, Stockholm, Sweden), folding endurance tester (Kumagai Riki Kogyo Co. Ltd., Tokyo, Japan), tearing resistance tester (Thwing-Albert Instrument Co. Ltd., West Berlin, USA), and tensile tester (EJA-series; Thwing-Albert Instrument Co. Ltd., West Berlin, USA), respectively.

Using the same handsheet making and testing methods mentioned above, a set of 10 handsheets was produced from commercial bleached hardwood, softwood, and cotton pulp fibers, before determining their properties. With a basis weight of $90 \mathrm{~g} / \mathrm{m}^{2}$, a set of 10 handsheets produced from bleached Coi pulp and cotton pulp fiber were used to compare their physical and mechanical properties. This was done as a feasibility study on using Coi pulp fiber as a unique fibrous raw material in future Thai banknote paper production.

\section{RESULTS AND DISCUSSION}

\section{Microscopic Observations of the Sheet Sample of Coi Handmade Paper}

Figure 2(a) shows the microscopic view of the sheet sample of Coi handmade paper. There is film-like material bridging the fibers, both on the surface of the paper and in its structure. This film-like material possibly originated from the gum found in the Coi bark, which is used in pulp fiber production without any degumming pretreatment. Coupled with a high felting power of Coi pulp fiber, the film-like material possibly plays a key role in providing the strength of the wet sheet during the manufacture of Coi handmade paper. Furthermore, there are numerous cubic calcium particles left throughout the surface of the paper, as indicated by the EDX peaks in Fig. 2(b). These observations are consistent with previous research (Boonpitaksakul et al. 2019). 

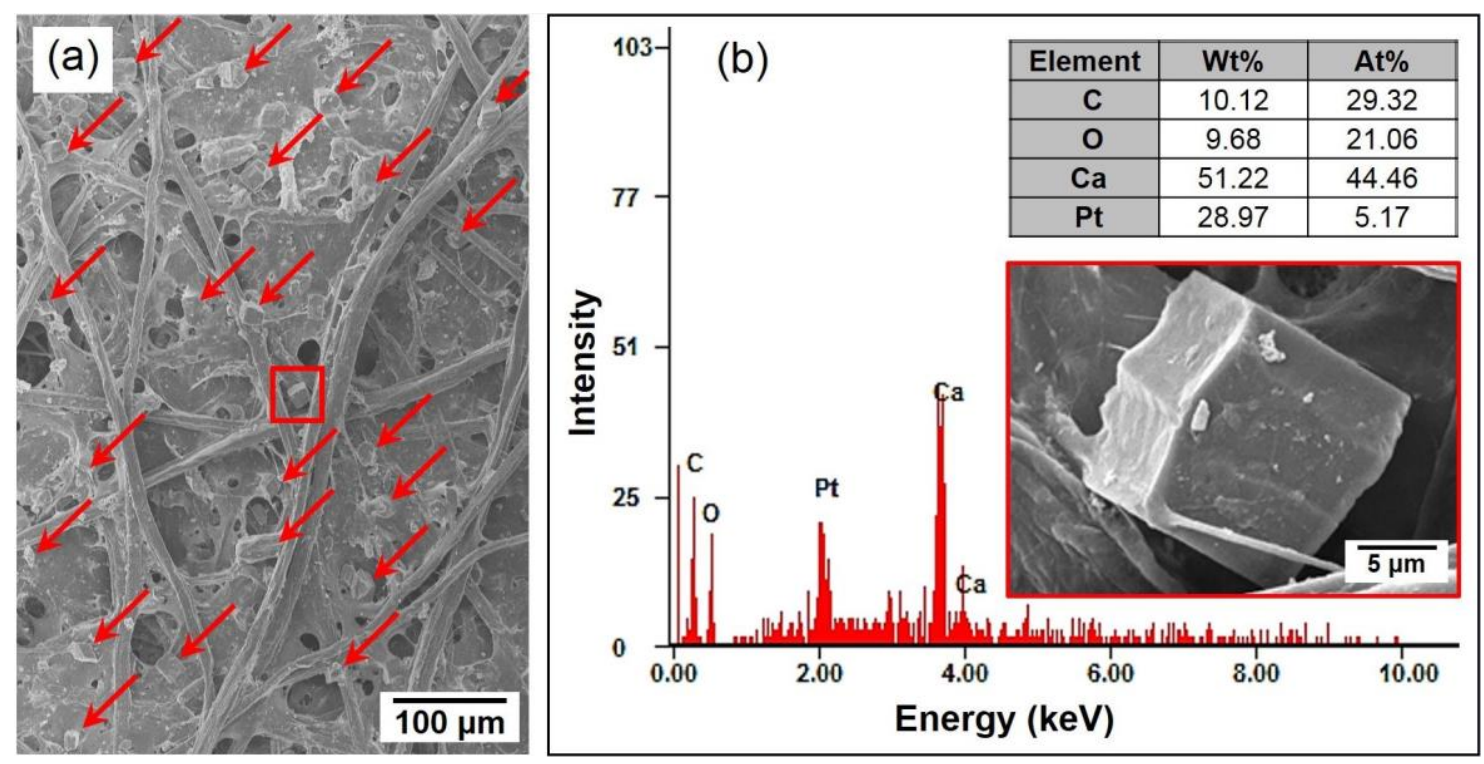

Fig. 2. (a) An SEM image showing film-like material and cubic calcium particles remaining on the sheet sample of Coi handmade paper (indicated by arrows). The square referred the exact position for EDX analysis; (b) EDX result confirming the appearance of a cubic calcium particle.

\section{Handsheet Making and Testing}

Figure 3 demonstrates the changes in pulp fiber and handsheet characteristics due to beating. All handsheets produced with the beaten pulp fibers were denser and smoother than those produced from unbeaten ones, even though the Coi pulp fibers and some cotton pulp fibers in the handsheets were not as flattened as those from hardwood and softwood pulp fiber, due to the beating effect. This result agreed with the fiber morphology reported in previous research (Boonpitaksakul et al. 2019), where the fiber length, slenderness ratio, and Runkel ratio of Coi pulp fiber were higher than those of hardwood, softwood, and cotton linter, respectively, while its flexibility was lower. This means that the Coi pulp fiber possesses a high felting power with low flexibility and collapsibility of the fiber wall (Tofanica et al. 2011).

Additionally, some of the cotton pulp fibers in the handsheets were flattened slightly upon beating treatment. This could be postulated as being due to the presence of cotton lint, which has a high slenderness ratio and a low flexibility. Furthermore, direct use of Coi bark strips regardless of degumming pretreatment possibly generated the film-like material left on the surface of the handsheet produced from both the beaten and unbeaten Coi pulp fiber, as indicated in Fig. 3. Therefore, the film-like material is expected to strengthen the handsheets.

Mou et al. (2013) suggested that the film between fibers was possibly formed of extracellular material including polysaccharides, extractives, and very fine cellulosic fibrils. Cubic calcium particles were also observed on the handsheet surface. These observations are consistent with those found on the surface of the sheet sample of Coi handmade paper (Fig. 2) and in previous research. 

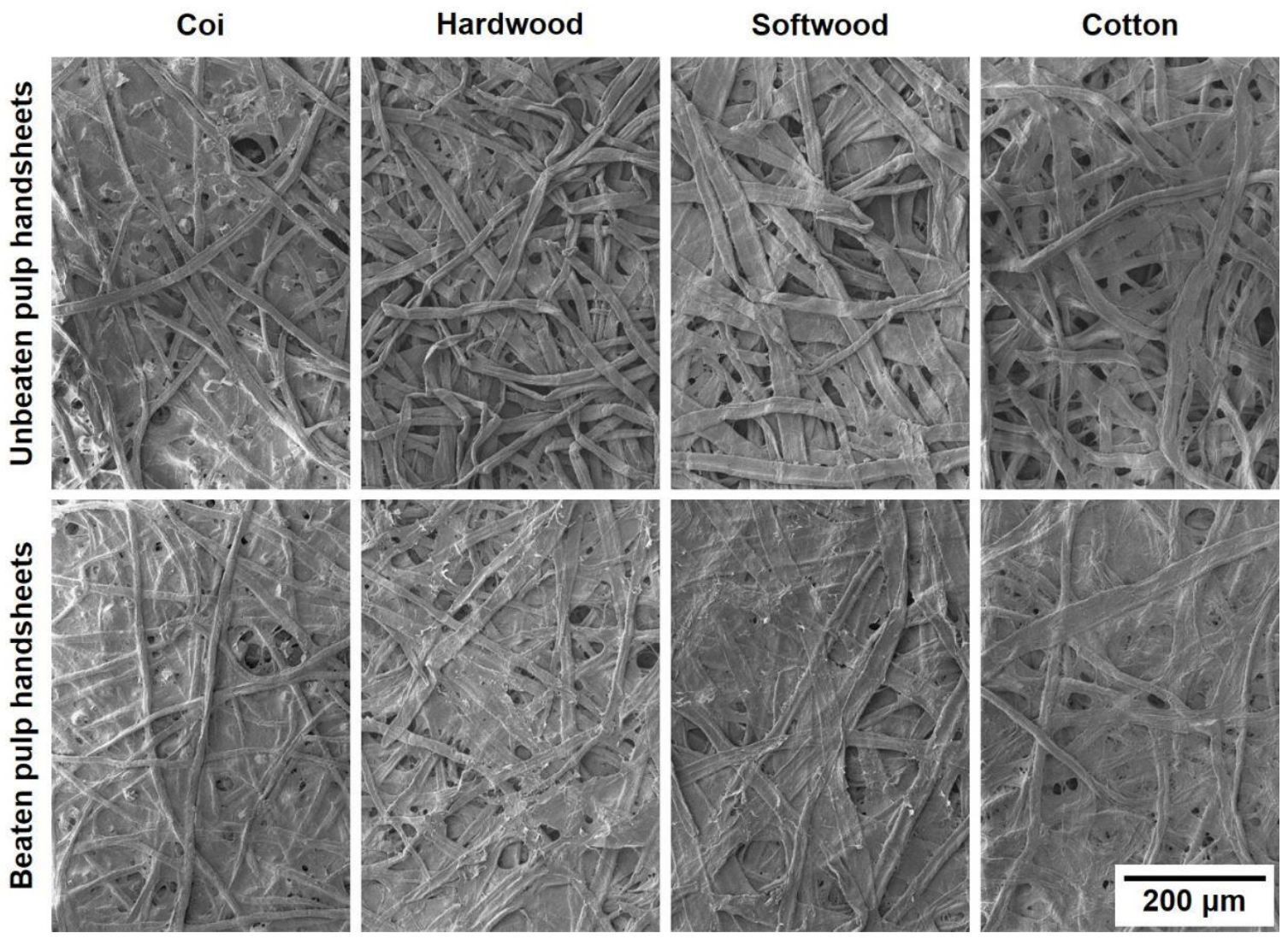

Fig. 3. SEM micrographs at $200 \times$ magnification showing the surface of laboratory handsheets (basis weight $=60 \mathrm{~g} / \mathrm{m}^{2}$ ) produced from unbeaten and beaten (beating time $=45 \mathrm{~min}$ ) pulp fibers of Coi, hardwood, softwood, and cotton, respectively.

Figure 4 (a) and (b) demonstrate changes in the freeness and apparent density of handsheets due to beating. Unbeaten Coi pulp fibers exhibited a lower Canadian Standard Freeness (mL CSF) than the other pulp fibers derived from hardwood, softwood, and cotton. The film-like material in Coi pulp fibers promoted layer-connections between fibers, producing a film-like layer covering the surface of a handsheet, as demonstrated in Fig. 3. This was even though the length of the fiber was very long and did not collapse well due to thick cell walls and small lumens (Boonpitaksakul et al. 2019). Thus, voids did not occur frequently between fibers compared with the other pulp fibers. Additionally, Fig. 3 also shows calcium cubic particles, which reduce the drainability of Coi pulp fiber by filling the voids between fibers. Without a film of gel-like material covering the surface of the handsheet, cotton pulp fiber offered the highest freeness, while softwood and hardwood pulp fibers exhibited lower levels of freeness, as shown in Fig. 3. As is well known from other research, beating decreased the freeness of all the pulp fibers, while consequently increasing the apparent density of the handsheets. This is because the occurrence of internal delamination and fibrillation of the pulp fibers, increasing bonding surface area and collapsibility upon beating.

Figure 4 (c) and (d) show changes in the brightness and opacity of handsheets due to beating. In general, it was observed that denser handsheets produced from beaten pulp fibers had a lesser number of air voids in their structure. This property normally results in a lower brightness due to poor scattering of light through the structure (Khantayanuwong et al. 2017). Thus, a decrease in brightness of the handsheets could be a result of beating. 
Furthermore, an initial lowering of brightness and increase in opacity of handsheets derived from Coi pulp fiber was observed, which as possibly due to light absorption by the filmlike material and cubic calcium particles found on the surface of handsheets, when compared to the handsheets derived from other pulp fibers. Varhimo (2013) demonstrated that a decrease in the brightness of mechanical pulp bleached by a peroxide in the wet end section of a paper machine was possibly due to the light absorbing material dissolved in and colloidal substance on the surface of the fiber.

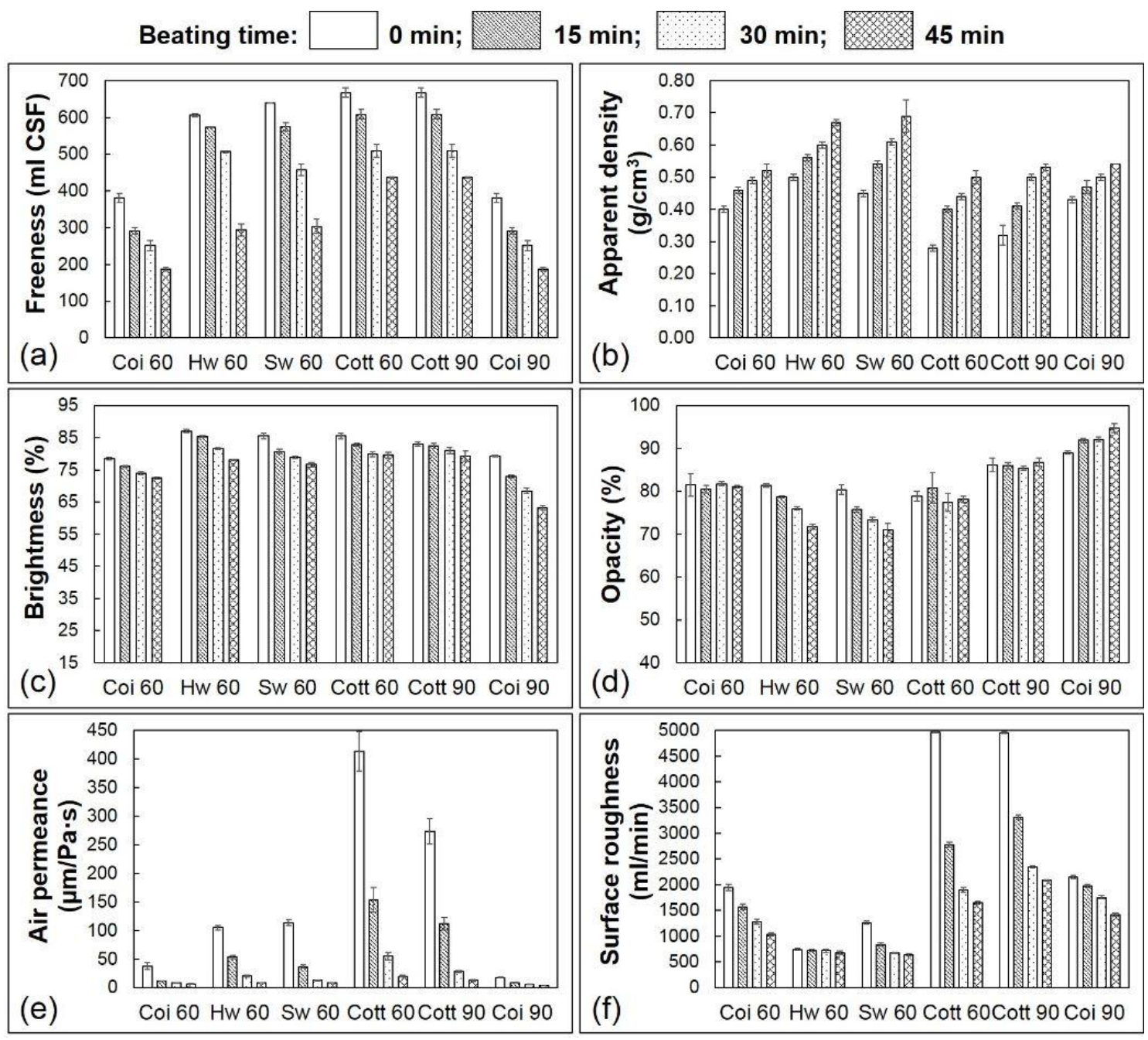

Fig. 4. Changes in the freeness (a), apparent density (b), brightness (c), opacity (d), air permeance (e), and surface roughness of handsheets due to beating; The data are shown as mean $\pm 95 \%$ confidence interval; $\mathrm{Hw}=$ hardwood; $\mathrm{Sw}=$ softwood; Cott = cotton; $\mathrm{B}=$ bleached; UB $=$ unbleached; $60=60 \mathrm{~g} / \mathrm{m}^{2} ; 90=90 \mathrm{~g} / \mathrm{m}^{2}$.

Changes in air permeance and surface roughness of handsheets are shown in Fig. 4 (e) and (f). Even though Coi and cotton pulp fiber were very long and did not collapse well caused by the thick cell walls and small lumens, as demonstrated by Boonpitaksakul et al. (2019), Coi pulp fiber handsheets possessed a lower air permeance and surface roughness. This was possibly because of the film-like material promoting layer-connections between fibers and a film-like layer covering the handsheet surface, as demonstrated in Fig. 3. Thus, a lesser number of voids between fibers and smoother surface of the Coi pulp fiber 
handsheets were observed when compared to those produced from cotton pulp fibers. Additionally, Fig. 3 also shows the presence of calcium cubic particles, which could play a role in decreasing the air permeance of handsheet produced from Coi pulp fiber by filling the voids between fibers. Thus, without a film of gel-like material covering the surface of a handsheet, the cotton pulp fiber had the highest air permeance and surface roughness, while handsheets drawn from hardwood and softwood pulp fibers had a relatively lower air permeance and surface roughness. Beating lowered the air permeance and surface roughness of all the pulp fibers and the derived handsheets.

There was an increase in mechanical properties of handsheets, i.e., tensile index, tensile energy absorption (TEA), modulus of elasticity, burst index, and folding endurance, due to beating, as shown in Fig. 5 (a)-(e). Beating provided fibrillation to the pulp fibers, increasing the surface area and collapsibility of pulp fiber, as seen in Fig. 3, i.e., the denser handsheets had a higher strength. Furthermore, according to the reasons described above, Coi pulp fiber possesses a higher felting power and film-like material, promoting layerconnections between fibers and a film-like layer covering the surface of a handsheet. This results in better mechanical properties even without any beating. Therefore, without beating, a higher strength can be obtained for Coi pulp fiber handsheets as was obtained in the past in Thailand around 330 years ago. These observations are consistent for Thai long books or Samud Coi (Coi book), which were produced by folding Coi paper in and out like a fan (Boonpitaksakul et al. 2019). Nevertheless, the effect of beating on the strength of handsheets produced from Coi pulp fiber was minimal due to the inferior flexibility and collapsibility of fiber wall. The lowering in strength of handsheets produced from cotton pulp fiber through beating was also possibly due to the same reasons. On the other hand, the strength development of handsheets derived from hardwood and softwood fibers was a bit different. Higher flexibility and collapsibility of both wood fibers innately provided superior strength properties for their derivative handsheets.

Figure 5 (f) shows the changes in tearing resistance of handsheets due to beating. With the long pulp fibers of Coi, softwood, and cotton, the tearing resistance of the respective handsheets was higher than that of the handsheets produced from the shorter fibers of hardwood. Furthermore, there was a reduction in the tearing resistance of handsheets produced from long pulp fibers, i.e., Coi and softwood, possibly due to the fiber being cut by beating. This is because the tearing resistance generally relies on pulp fiber length, i.e., handsheets derived from long fibers have a higher tearing resistance with high frictional drag force per fiber (Brandon 1981). Shorter fiber length of hardwood pulp is seemingly not affected by fiber cutting as a result of the beating process. However, the tearing resistance of handsheets produced from both hardwood and cotton pulp fibers initially increased but finally decreased due to the shortening effect. With a higher degree of interfiber bonding, the increase in tearing resistance of handsheets depends on the fiber strength, which could reduce after beating (Levlin 1999).

From the results demonstrated above and those demonstrated in previous research (Boonpitaksakul et al. 2019), Coi pulp fiber can be used to make to paper without any further chemical and physical treatments, i.e., chemical and energy saving could be expected, with moderate levels of freeness. Coi paper produced from both beaten and unbeaten Coi pulp fiber also possesses the general attributes of good quality for paper making with high strength, especially folding endurance, whereas Samud Coi was produced and used by folding Coi paper in and out like a fan. These observations are consistent with the fact that most of Coi paper and Samud Coi, used as archive materials in the museum and age over a few hundred years, exhibit the potential use of Coi pulp fiber 
as a new material in modern papermaking. It is also worth mentioning how the Siamese (or Thai people) used the bark from Coi tree and from paper mulberry tree for producing pulp fiber and handmade paper in the ancient times. This is even when both the trees are quite different in their morphology but are classified under the same Family of Moraceae.

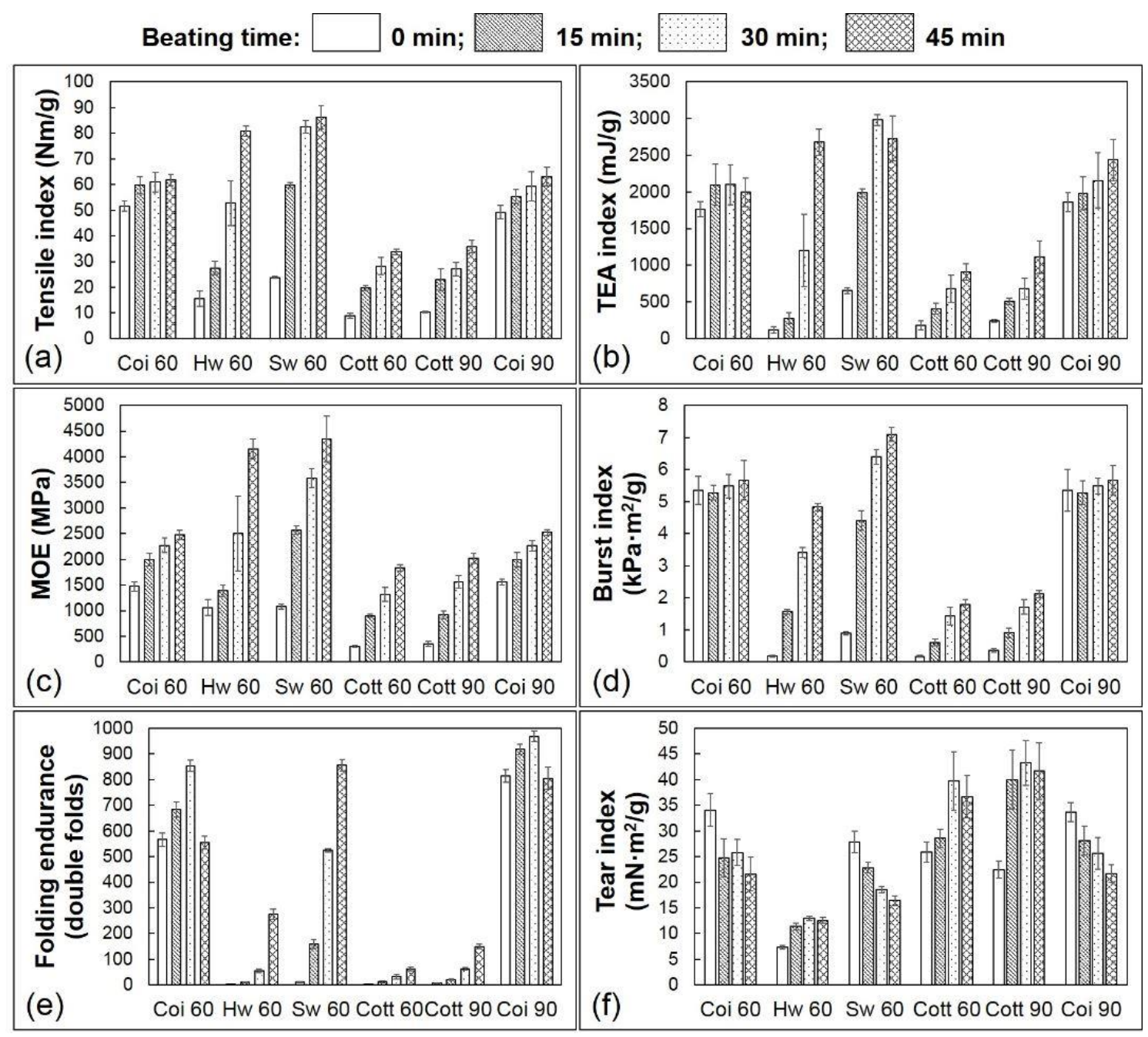

Fig. 5. Changes in the mechanical properties of handsheets due to beating; the data are shown as mean $\pm 95 \%$ confidence intervals; $\mathrm{Hw}=$ hardwood; $\mathrm{Sw}=$ softwood; Cott $=$ cotton; $\mathrm{B}=$ bleached; UB = unbleached; $60=60 \mathrm{~g} / \mathrm{m}^{2} ; 90=90 \mathrm{~g} / \mathrm{m}^{2}$.

Furthermore, at $90 \mathrm{~g} / \mathrm{m}^{2}$ of basis weight, the handsheets derived from Coi pulp fiber have tensile and bursting strength as well as folding endurance, which are higher than handsheets derived from cotton pulp fiber. However, beating could decrease the tearing strength of handsheets derived from Coi pulp fiber. Surface smoothness of Coi handsheets was also observed. Therefore, these attributes indicate to further studying the application of Coi pulp fiber in producing a unique Thai banknote paper. Additionally, the unique presence of cubic calcium particles on the surface of paper produced from Coi pulp fiber would be useful in preventing counterfeiting of banknotes. 


\section{CONCLUSIONS}

1. This study reports the microscopic observations of the surface of Coi handmade paper obtained from the traditional production performed in a folk arts and crafts center in Thailand. Film-like material and cubic calcium particles were observed on the surface, which is consistent with previous research.

2. The physical properties of handsheets derived from Coi pulp fiber are shown for the first time, and they would be fundamentally useful in archeological and industrial applications. Both beaten and unbeaten Coi pulp fiber can be used to make handsheets a high strength, i.e., without further beating and chemical treatment, savings of chemical and energy can be expected.

3. There are some interesting aspects of Coi pulp fiber to produce a unique Thai banknote paper. The presence of cubic calcium particles on the surface of paper produced Coi pulp fiber would be useful in anti-counterfeiting of banknotes.

\section{ACKNOWLEDGMENTS}

The authors would like to express their sincere gratitude to Ko Koet Royal Folk Arts and Crafts Center, Thai Paper Co., Ltd., the Bank of Thailand, and the Environment Pulp and Paper Co., Ltd. for providing the sheet sample of Coi handmade paper, commercial pulp fibers, and $\mathrm{ClO}_{2}$ solution used in this research. The authors are also grateful for the financial support from the Kasetsart University Research and Development (KURDI).

\section{REFERENCES CITED}

Boonpitaksakul, W., Chitbanyoung, K., Puangsin, B., Pisutpiched, S., and Khantayanuwong, S. (2019). "Natural fiber derived from Coi (Streblus asper Lour.) and their behavior in pulping and as paper," BioResources 14(3), 6411-6420. DOI: 10.15376/biores.14.3.6411-6420

Brandon, C. E. (1981). "Paper properties," in: Pulp and Paper-Chemistry and Chemical Technology (Volume 3), J. Casey (ed.), John Wiley \& Sons, New York, USA.

Hubbe, M., and Bowden, C. (2009). "Handmade paper: A review of its history, craft, and science," BioResources 4(4), 1736-1793. DOI: 10.15376/biores.4.4.1736-1793

ISO 5269-1 (2005). "Pulp - Preparation of laboratory sheets for physical testing-Part 1: Conventional sheet-former method," International Organization for Standardization, Geneva, Switzerland.

ISO 5636-3 (1992). "Paper and board - Determination of air permeance (medium range) - Part 3: Bendtsen method," International Organization for Standardization, Geneva, Switzerland.

Khantayanuwong, S., Khemarom, C., and Salaemae, S. (2017). "Effects of shrimp chitosan on the physical properties of handsheets," Agriculture and Natural Resources 51, 53-56. DOI:10.1016/j.anres.2016.07.006

La Loubère, S. (1963). A New Historical Relation of the Kingdom of Siam, Bell \& Howell Company, Cleveland, OH, USA. 
Levlin, J. E. (1999). "General physical properties of paper and board," in: Pulp and Paper Testing, J. E. Levlin and L. Söderhjelm (eds.), Fapet Oy, Helsinki, Finland.

Mou, H., Iamazaki, E., Zhan H., Orbin E., and Fardim, P. (2013). “Advanced studies on the topochemistry of softwood fibres in low-consistency refining as analyzed by FESEM, XPS, and ToF-SIMS," BioResources 8(2), 2325-2336. DOI: 10.15376/biores.8.2.2325-2336

Srivorapot, B., and Saengtub, P. (1999). Samud Coi, Office of the Welfare Promotion Commission for Teachers and Education Personnel, Bangkok, Thailand. (in Thai)

TAPPI T 200 sp-10 (2010). "Laboratory beating of pulp (Valley beater method)," TAPPI PRESS, Atlanta, GA, USA.

TAPPI T 220 sp-10 (2010). "Physical testing of pulp handsheets," TAPPI PRESS, Atlanta, GA, USA.

TAPPI T 227 om-09 (2009). "Freeness of pulp (Canadian standard method)," TAPPI PRESS, Atlanta, GA, USA.

TAPPI T 236 om-06 (2006). “Kappa number of pulp,” TAPPI PRESS, Atlanta, GA, USA.

TAPPI T 403 om-10 (2010). "Bursting strength of paper,” TAPPI PRESS, Atlanta, GA, USA.

TAPPI T 411 om-08 (2008). "Thickness (caliper) of paper, paperboard, and combined board," TAPPI PRESS, Atlanta, GA, USA.

TAPPI T 414 om-04 (2004). "Internal tearing resistance of paper (Elmendorf-type method)," TAPPI PRESS, Atlanta, GA, USA.

TAPPI T 425 om-11 (2011). "Opacity of paper (15/d geometry, illuminant $A / 2^{\circ}, 89 \%$ reflectance backing and paper backing," TAPPI PRESS, Atlanta, GA, USA.

TAPPI T 452 om-08 (2008). "Brightness of pulp, paper, and paperboard (directional reflectance at $457 \mathrm{~nm})$," TAPPI PRESS, Atlanta, GA, USA.

TAPPI T 460 om-11 (2011). "Air resistance of paper (Gurley method)," TAPPI PRESS, Atlanta, GA, USA.

TAPPI T 494 om-06 (2006). "Tensile properties of paper and paperboard (using constant rate of elongation apparatus)," TAPPI PRESS, Atlanta, GA, USA.

TAPPI T 511 om-08 (2008). "Folding endurance of paper (MIT tester)," TAPPI PRESS, Atlanta, GA, USA.

TIS 1054-2552 (2009). “Xerographic papers,” Thai Industrial Standard, Bangkok, Thailand. (in Thai)

Tofanica, B. M., Cappelletto, E., Gavrilescu, D., and Meuller, K. (2011). "Properties of rapeseed (Brassica napus) stalks fibers," Journal of Natural Fibers 8(4), 241-262. DOI: $10.1080 / 15440478.2011 .626189$

Varhimo, P. U. (2013). Brightness Reduction of Peroxide-bleached Mechanical Pulp and Fillers in the Wet End of a Paper Machine, Doctoral Dissertation, Aalto University, Helsinki, Finland.

Veeraprachak, K. (1987). Thai Long Book Production and Palm leaf Manuscripts Preparation, Fine Art Department of Thailand, Bangkok, Thailand. (in Thai)

Article submitted: April 22, 2021; Peer review completed: June 20, 2021; Revised version received: July 4, 2021; Accepted: July 21, 2021; Published: July 25, 2021. DOI: 10.15376/biores.16.3.6201-6211 